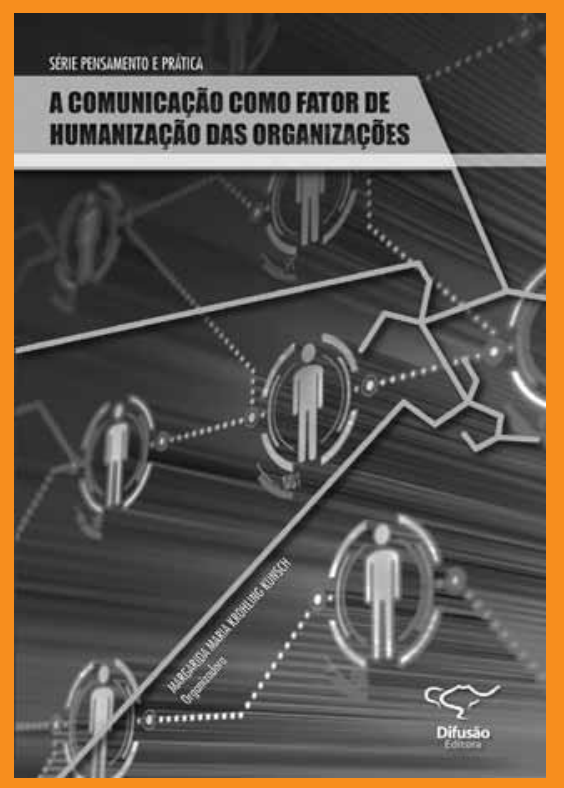

A comunicação como fator de humanização nas organizações

Margarida M. Krohling Kunsch (Org.)

São Caetano do Sul, SP:

Difusão Editora, 2010

258 páginas

Resenhado por:

Claudia Nociolini Rebechi

- Doutoranda e mestre pelo Programa de Pós-Graduação em Ciências da Comunicação da Escola de Comunicações e Artes da Universidade de São Paulo (ECA-USP)

- Especialista pelo Curso de Pós-graduação Lato Sensu de Gestão Estratégica em Comunicação Organizacional e Relações Públicas (Gestcorp), do Departamento de Relações Públicas, Propaganda e Turismo da ECA-USP

- Graduada em Comunicação Social com habilitação em Relações Públicas pela Universidade Estadual Paulista (Unesp)

- Professora da Faculdade de Comunicação da Universidade Metodista de São Paulo (Umesp)

•nociolini@hotmail.com 


\section{Comunicação, humanização e organização: uma tríade contemporânea?}

\section{Communication, humanization and organization: a contemporaneous triad?}

\section{Comunicación, humanización y organización: ¿una tríade contemporánea?}

ota-se, atualmente, certa preocupação de estudiosos brasileiros das áreas de comunicação organizacional e de relações públicas em entender melhor os elementos relativos à atividade humana no contexto das organizações. Diversas manifestações desse interesse têm sido explicitadas e procuram trazer à tona reflexões sobre possíveis relações entre comunicação, humanização e organização.

O livro A comunicação como fator de humanização das organizações se apresenta como uma dessas expressões e propicia ao leitor uma série de ideias e considerações a respeito dessa temática tão complexa e significativa quando se pretende tratá-la de forma séria e crítica. Essa obra, organizada pela professora titular da Universidade de São Paulo e já conhecida pesquisadora Margarida Maria Krohling Kunsch, sistematiza as principais discussões geradas no III Congresso Brasileiro Científico de Comunicação Organizacional e Relações Públicas, realizado pela Associação Brasileira de Pesquisadores da Comunicação Organizacional e de Relações Públicas (Abrapcorp) nos dias 28, 29 e 30 de abril de 2009, na cidade de São Paulo.

Dois são os eixos temáticos que compõem a publicação: 1) a organização como espaço de diálogo e construção de significado; e 2) a comunicação como lugar e processo de humanização da organização nas relações de trabalho. Cada um deles é representado por sete artigos. Ou seja, são ao todo quatorze textos produzidos por estudiosos, em sua maioria brasileiros, mas, também, se destacam pesquisadores de outros países que participaram do congresso. O leitor perceberá que esses artigos não necessariamente convergem para um mesmo ponto de vista quanto à temática constitutiva do livro, o que, a meu ver, é um dos mais relevantes aspectos da obra no sentido de contribuir para o debate contemporâneo desse assunto, que há tempos tem tangenciado determinadas áreas de conhecimento. 
Sabemos que o interesse pelas relações entre o que é concernente ao homem e à organização não é algo inédito, seja no Brasil ou no exterior, especialmente quando nos referimos aos estudos ligados à administração organizacional e à gestão das formas de organização do trabalho. Mesmo quando a atividade de comunicação é recordada nesse contexto, é possível observar o tratamento desse assunto na literatura que abrange os estudos organizacionais, por exemplo. Isso se dá, entre outras razões, porque a racionalidade das organizações, tão importante aos seus processos de produção e de desenvolvimento, depende diretamente da atividade humana e, consequentemente, das relações de comunicação que a concretizam.

O livro aqui apresentado retoma o debate em torno dessa questão, buscando contemporizá-la frente à perspectiva brasileira da área da comunicação organizacional que dá luz ao projeto de humanização das organizações a partir da comunicação. O próprio título da obra explicita esse propósito ao indicar a comunicação como uma espécie de conciliadora desses dois processos - humanização e organização -, que para alguns autores da publicação parece ser possível, enquanto para outros ainda restam dúvidas.

A heterogeneidade do tratamento desse assunto no conjunto dos artigos é rica, possibilitando ao leitor confrontar os pontos de vista dos autores e refletir sobre duas perguntas-chave que a obra permite trazer à tona: 1) humanização e organização são processos compatíveis?; 2) a comunicação pode ser considerada a principal mediadora entre os processos de humanização e organização?

Certamente, as prováveis respostas para essas perguntas dependerão do entendimento que temos sobre cada um dos componentes dessa tríade. Nesse sentido, os autores do livro nos trazem interessantes contribuições em seus artigos.

Na primeira parte do livro, Dennis K. Mumby, professor da University of North Carolina, por exemplo, ao construir o seu texto "Reflexões críticas sobre comunicação e humanização nas organizações", desenvolve suas ideias a partir da abordagem conceitual intitulada "estudos organizacionais críticos". Em suma e de maneira bastante simples, esta perspectiva se interessa por analisar criticamente as relações entre poder e discursos na constituição das organizações. Sob essa égide, os processos comunicacionais são compreendidos como políticos, reproduzindo ou recusando determinados interesses e certas estruturas de poder. E a humanização é enxergada mais claramente quando são aceitas as diferenças nesses processos. Tais iferenças são estabelecidas a partir de uma multiplicidade de visões oriundas de diversas classes sociais, gêneros, etnias etc. Nota-se na fala de Mumby que essa abordagem crítica tenciona revelar - e questionar - a preocupação principal das organizações no que tange à eficiência e à produtividade, evidenciando o desprezo destas pela condição humana. 
Em outro momento da obra, entre os sete artigos que integram seu segundo eixo temático, temos as exposições de Marlene Regina Marchiori - professora da Universidade Estadual de Londrina (UEL) - e de Valéria Raimundo - professora da Universidade Federal de Minas Gerais (UFMG). Ambas trazem ao leitor considerações e reflexões sobre a comunicação e a humanização nas relações de trabalho em contextos organizacionais a partir de estudos empíricos que realizaram - aspecto, aliás, que demarca a segunda parte deste livro.

A professora da UFMG, em seu artigo nomeado "Interações comunicacionais no processo de trabalho de call centers", apresenta os principais resultados da pesquisa que produziu com centrais de relacionamento de duas organizações localizadas em Minas Gerais, sendo uma de capital privado e outra de capital misto. Contrariando uma das principais premissas de seu estudo, a estudiosa constatou que a comunicação nessas organizações está norteada pelas perspectivas "instrumental" e "reguladora". Isto é, os resultados de sua investigação apontaram um aspecto bastante claro quanto ao "controle" da gestão da comunicação nessas organizações que ignoram as perspectivas dialógica e relacional, destacadas como essenciais nos processos de interação dos sujeitos com as organizações em que trabalham.

De outro lado, temos a pesquisa empírica apresentada pela estudiosa Marlene Marchiori no artigo "Comunicação como expressão da humanização nas organizações da contemporaneidade". Suas considerações parecem apontar uma percepção contrária às conclusões do estudo realizado por Valéria Raimundo, pois mostram que "a gestão da comunicação vem acompanhando a contemporaneidade da área, estimulando-se processos de interação nas organizações" (p.147). O estudo exploratório desenvolvido pela professora da UEL realizou uma análise sobre a comunicação e a humanização nos ambientes de trabalho das organizações contempladas na edição de 2008 do Guia Exame das 150 melhores empresas para se trabalhar. A partir das respostas de 57 (38\% da mostra) dos gestores dessas empresas que lidam com programas e ações de "comunicação interna", a autora considera que há, sim, certa preocupação das orgaizações quanto à humanização.

Esta é somente uma pequena amostra do fértil debate que a obra propicia. $\mathrm{O}$ leitor poderá, também, conhecer as ideias e os pensamentos de estudiosos e pesquisadores sobre a temática que envolve a tríade comunicação, humanização e organização, como: Margarida Maria Krohling Kunsch (USP), Rudimar Baldissera (UFRGS), João José Azevedo Curvello (UCB), Roseli Figaro (USP), Elizabeth L. Toth (Universidade de Maryland/ EUA), dentre outros. 